OPEN ACCESS

Edited by:

Anna Occhipinti-Ambrogi,

University of Pavia, Italy

Reviewed by:

Paolo Vassallo,

Università di Genova, Italy

Maria Sini,

University of the Aegean, Greece

${ }^{*}$ Correspondence:

Marnie L. Campbell marnie.campbell@murdoch.edu.au

Specialty section

This article was submitted to Marine Ecosystem Ecology, a section of the journal

Frontiers in Marine Science

Received: 01 May 2018 Accepted: 27 June 2018

Published: 23 July 2018

Citation:

Campbell ML and Hewitt CL (2018) Which Values Do Non-Native Marine

Species Affect? A Case-Study Exploration of Perceived Values at

Threat in Micronesia.

Front. Mar. Sci. 5:247.

doi: 10.3389/fmars.2018.00247

\section{Which Values Do Non-Native Marine Species Affect? A Case-Study Exploration of Perceived Values at Threat in Micronesia}

\author{
Marnie L. Campbell ${ }^{1,2 *}$ and Chad L. Hewitt ${ }^{1,3}$ \\ ${ }^{1}$ National Centre for Marine Conservation and Resource Sustainability, University of Tasmania, Newnham, TAS, Australia, \\ ${ }^{2}$ Harry Butler Institute, Murdoch University, Murdoch, WA, Australia, ${ }^{3}$ School of Science, Faculty of Science and Engineering, \\ University of Waikato, Hamilton, New Zealand
}

Impact assessment of non-native species introductions tend to focus on either economic and/or environmental risks. We present work that extends these approaches bringing environmental (ecological) and economic values together with social and cultural considerations. Our approach aims to better inform future non-native species management risk analyses. A triangulation approach involving literature and museum searches, face to face discussions, and questionnaires was undertaken to identify values perceived to be at risk with the arrival of non-native marine species (NMS) in three countries in Micronesia (Guam, the Republic of Palau and Saipan). We identified value sets for a range of stakeholders and subsequently used scenario approaches to determine the values' perceived relative worth (non-monetary) and directional change of worth following a biosecurity incursion. We identified 337 value sub-elements, of which at least $40 \%$ are thought to be at risk (their worth would diminish) if a NMS introduction were to occur. Results were used to create Venn diagrams and value networks to aid in understanding the linkages between social, cultural, economic, and environmental values. Additionally the relationship between elicited values and their alignment to Ecosystem Service contribution is identified and discussed. The Venn diagrams and value networks should prove a beneficial tool for understanding citizen concerns around perceived biosecurity risks and developing effective future biosecurity risk communication strategies.

Keywords: alien species, ecosystem services, impact, marine biosecurity, non-native marine species, risk perception, the economics of ecosystems and biodiversity, values

\section{INTRODUCTION}

Researchers most often focus on biological or ecological effects when examining the influence that non-native marine species (NMS) have in regions where they are newly introduced (e.g., Ruiz et al., 1997, 1999; Huxel, 1999; Gurevitch and Padilla, 2004). Yet NMS can also have significant real and perceived impacts on human health, economic, social, and cultural attributes and activities (e.g., Hewitt, 2003; Jay and Morad, 2006; Lui et al., 2011; Campbell and Hewitt, 2013; Davidson et al., 2015; Ojaveer et al., 2015). The inclusion of social and cultural values with perceptions 
when considering risk is an important tenet of sustainability (Elliott, 2013; Elliott et al., 2014; Diaz et al., 2018), as it informs environmental and biosecurity managers of citizens' expectations and political will. In many instances, impacts on socio-economic, or cultural attributes and activities are not clear, and instead the perception of effect is used to infer impact. This is because a perceived effect can have as much influence on an individual's attitudes as real (or demonstrated) impacts and are a valid substitute in a socio-political context (e.g., Slovic, 1987; Campbell, 2008; Turvey et al., 2010; Cliff and Campbell, 2012; Campbell and Hewitt, 2013).

The validity of assessing perceptions, specifically risk perceptions, has been clearly demonstrated in other disciplines (Slovic, 1987, 2000; Sheeran and Orbell, 1999). Insights from these types of studies provide a foundational ability to understand and anticipate people's responses to a hazard. Drawing parallels from these studies, understanding the attributes, experiences, and/or activities (herein we refer to these collectively as values, or singularly as a value) that people feel will be affected by NMS is essential to improve management and decision-making around NMS. Our definition of "values" is similar to Reser and Bentrupperbäumer (2005) definition of "environmental values" but also encompasses economic, social and cultural attributes that are shared by individuals and communities, and are based upon beliefs, norms and judgements, creating a specific lenses for consideration (Diaz et al., 2018). An understanding of critical values for a population, coupled with understanding people's responses to a threat to these values, creates the opportunity to construct a holistic, biosecurity risk management framework for the management of the hazard response.

The driving factors associated with intentional and unintentional introductions of species and further spread (secondary transfers) can be better understood by ascertaining people's motivations, actions and beliefs (e.g., Cliff and Campbell, 2012). This knowledge can potentially to be used to improve post-border management of marine biosecurity issues. This approach is especially pertinent when the public are potentially hostile to changes that they feel affect them and that they feel are foisted upon them by decision-makers. This point is effectively illustrated through a number of well publicized risk or hazard perception analyses that are focused on technology (e.g., nuclear power; Slovic, 1987), or climate change (e.g., Kempton, 1991). Few studies have gauged the public's perception and subsequent reactions to the potential threat of a non-native aquatic species (but see Cliff and Campbell, 2012). In such instances, assessment needs to be inclusive of values across multiple themes (environmental, economic, social, and cultural).

This research evaluates values that are perceived to be affected by NMS and categorizes them in two frames: a) across the four values sets of environmental (ENV), economic (ECON), social (SOC) and cultural (CULT); and b) aligned to The Economics of Ecosystems and Biodiversity (TEEB) Ecosystem Services. The identified values are crucial within a risk assessment framework as they form the basis of a consequence (i.e., impact) assessment (e.g., Campbell, 2008; Campbell and Hewitt, 2013; Ojaveer et al., 2015). Consequence assessment relies on using an identified set of thresholds that help demarcate different levels of impact, ranging from negligible to extreme (e.g., Campbell, 2008; Campbell and Hewitt, 2013; Azmi et al., 2015; Ojaveer et al., 2015). Thresholds represent the "allowable level of risk (ALOR)" or "allowable level of protection (ALOP)" that provide a compromise or trade-off to the important question of "how much impact is acceptable." Accordingly, thresholds are determined by consensus across a population or group, whereas values are identified through individual perceptions.

Thresholds can be determined using different methods, such a Multi-Criteria Evaluation (MCE) (Munda et al., 1994), MultiCriteria Decision Analysis (MCDA) (Huan et al., 2011), or Deliberative Multi-Criteria Evaluation (DMCE) (Proctor and Drechsler, 2006; Lui et al., 2011) approaches, with the chosen methods needed to incorporate stakeholders perceptions with policy and legislative obligations (e.g., Campbell and Gallagher, 2007). We note however, that within this preliminary study we have focussed upon eliciting and identifying values, determining a values' perceived relative worth, and the perceived directional change in a values' worth following a biosecurity event. We did not determine specific thresholds, or undertake a formal risk assessment, as we see this as a next step in the process of developing a robust biosecurity risk assessment framework.

There were two specific aims for this research: (1) to identify known and perceived values that may be affected by the arrival of new NMS; and (2) to assess whether the perception of a values' worth would change if a new NMS was to occur in the region. We focus our study on Micronesia, specifically Guam, the Republic of Palau (referred to as Palau), and Saipan. The case study area was selected because the US Department of Defense (US DoD) made a decision to reduce the size of the forces based in Okinawa, Japan, and concurrently relocate personnel and associated infrastructure to Guam (Ruiz and Zabin, 2012). This would increase the military presence in Guam, with a potential increase in exposure to non-native species (in a marine context) via increased shipping. Following the announcement of the US DoD decision, protests, and riots ensued in Guam, with the public demonstrating their frustrations at lack of control and impending perceived threats from the expansion of forces in Guam.

We note that the US DoD commissioned a number of studies to examine the biosecurity risks associated with such a change, however, all had a biological focus (e.g., Ruiz and Zabin, 2012; Walsh et al., 2014). The marine risk analysis that occurred included an un-commissioned investigation of the perceived social, cultural, ecological and economic values that could be affected, implemented by the authors of the marine biosecurity risk assessment for Micronesia (Hewitt et al., 2012). The outcomes of this un-commissioned study are the focus of this article.

\section{MATERIALS AND METHODS}

The geographic focus was on Guam and two of its trading partners (the Republic of Palau and Saipan in the Northern Mariana Islands). All research was conducted under approval and followed National guidelines for human research ethics 
(University of Tasmania ethics approval reference \# H11233). We note that the results and patterns presented here are country relevant and cannot be extrapolated to other countries within or across Micronesia. Similarly, the findings are temporally limited to the period of the survey. However, the findings illustrate the complexity of non-native species risk assessment, which needs to be inclusive of a range values beyond ecological and/or economic.

\section{DATA COLLECTION AND ANALYSIS}

A four-staged approach was used to identify values (composed of sub-elements) and to investigate whether respondents perceived that these values would change once a NMS arrived in their region. Data was collected through literature and museum searches, face to face discussions and three questionnaires that were country-specific. Surveys and subsequent interviews used non-random purposive sampling (e.g., Babbie, 2007; Walter, 2010), with additional snowballing to increase participation. Our sampling frame was restricted to scientists, environmental managers, industry (shipping and tourism related), government officials, and public stakeholders who had declared an interest in NMS risk associated with the potential alterations in Guam vessel traffic due to the US DoD redeployment of troops to Guam. The sampling frame could not be fully identified as additional participants were identified as the sampling progressed. The process followed is illustrated in Figure 1, with a description following.

\section{Stage 1: Identify Values}

We used a triangulation process (e.g., Esterberg, 2002) to identify and clarify values. The initial step in our triangulation was faceto-face meetings and focus group interviews that occurred over a 1 month period. As well as elucidating participant's values, this step also directed us to further individuals to meet and interview. This led to the compilation of a draft interim list of values. Step 2 of the triangulation involved researching the literature, museum records, and relevant material that could help us substantiate the interim values and add further relevant values that may have been missed in step 1. The outcomes of these steps was the creation a draft list of values for each country (Guam, Palau or Saipan). This initial interview step involved holding standardized discussions (in the form of semi-informal interviews) to introduce the topic and provide a background on the research that was occurring.

Using this open discussion-based approach we could address issues around potential linguistic uncertainty (Regan et al., 2002) by providing a specific context for the research, and we ensured that participants understood the project and what was being asked of them. We encouraged participants to express their opinions and ideas related to the research topic, emphasizing that information provided remain anonymous. We did not seek consensus on the values identified, but instead collected a wide range of opinions in a social and cultural context (e.g., Campbell and Hewitt, 2013). Although the agenda for interviews was restricted to the research topic, the direction of the discussions was guided by the participants. Thus, participants were able to articulate what was important to them, to have more "power"

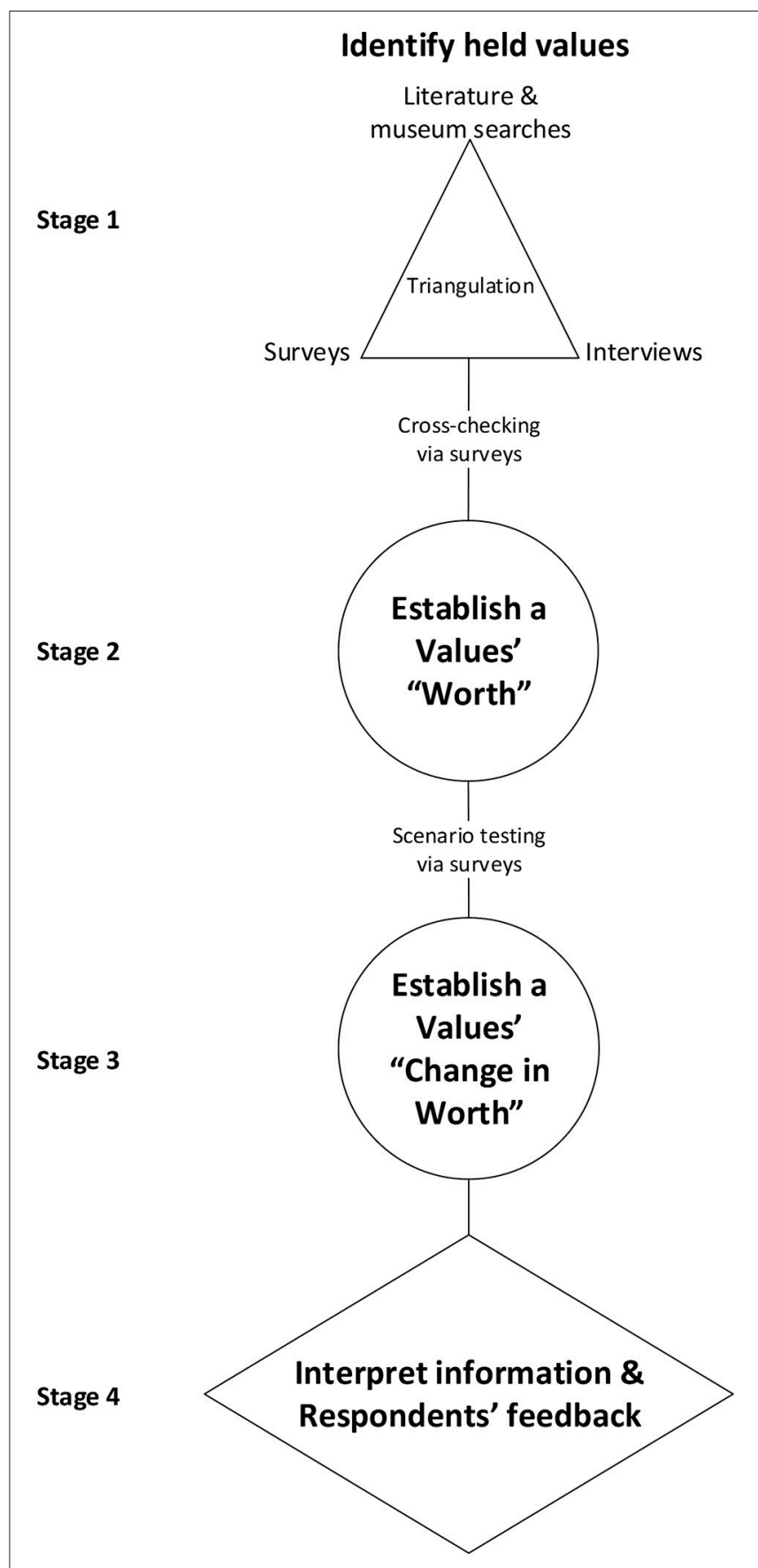

FIGURE 1 | The conceptualized data collection and interpretation process.

in the discussions, and subsequently influence the results by choosing what they would and would not discuss.

Stages 2 and 3 of data collection were explained to participants during the meetings and interviews. These stages were implemented online, with hard copy questionnaires also provided for those participants who did not wish to use an online survey. During Stage 1, scenarios based on known NMS introductions that had occurred in tropical systems were 
presented and discussed with the participants with the aim to prime participants for Stages 2 and 3.

\section{Stage 2: Establish Worth of Values}

Based on the values identified at Stage 1, we developed a questionnaire that asked participants to rate each identified value on a scale of "worth" to them as individuals $(1=$ low, $5=$ high). Participants were encouraged to add additional values that may have been missed in Stage 1, and to also rate any newly identified values on the same scale of worth to them. We note that the concept of worth did not have a dollar value associated with it or involve economic evaluation techniques (e.g., contingent valuation, hedonic pricing, travel cost, choice experiments, stated preference or benefit transfer; Adamowicz, 2004), but instead the concept of worth was used to infer a scale of importance to the respondent. This importance can be intrinsic (i.e., hold importance merely for being), utilitarian (i.e., holds an importance because it can used by humans [provides a service]), or a combination of these. This is scaled from low (1) to medium (3) to high (5) with the analysis joining low (1) and low-medium (2) together, and medium-high (4) and high (5) together.

The questionnaire was implemented online, with invitations sent to participants from Stage 1 asking them to please participate and to share the questionnaire with others that may also be interested in participating. Hard copy versions of the questionnaires were also provided to a number of identified incountry contact points for those participants that did not wish to use an online questionnaire.

\section{Stage 3: Establish Potential Changes in Worth}

The final stage in this process examined how perceptions of the identified values changed when challenged with a NMS arrival scenario. To investigate this, a scenario testing or a visioning exercise (e.g., Duinker and Greig, 2007) was implemented. Respondents were provided with a simple scenario (arrival of a NMS in their area) and asked if this arrival event would alter their view of the identified values (from Stage 1). If they answered "yes," then they were asked to rate how the value had changed. A decrease in value represented that that value' worth diminished to an individual than it had originally represented. In contrast, an increase in value represented an increase in worth of the identified value. Change in a values' worth (or lack thereof) could then be used to represent the consequence (i.e., inferred relative impact) of the arrival of a NMS in that person's area.

\section{Stage 4: Interpret Information and Request Respondents' Feedback}

An interpretive enquiry approach was utilized where information collected from the previous stages was interpreted from an introduced marine species context. A summary of the outcomes of the interpretation and data collected that listed the perceived values, the perceived values' worth and changes in worth was provided to respondents, with a request for feedback. The feedback is reflected in the final interpretation presented herein. Feedback is an integral component of the process that ensures that we accurately captured, interpreted and represented information. Participants could provide comments directly back to the researchers or provide comments to an identified incountry person that collated information and provided the information to the researchers. Respondent's feedback was unrestricted and could focus on the researchers' interpretation of the results, respondent's opinions around the researchers reasoning behind identified trends, and information pertaining to how the methods could be improved for future investigations.

All data collected was analyzed thematically and categorized into two frames: (1) across the four values sets of environmental, economic, social and cultural; and (2) aligned to The Economics of Ecosystems and Biodiversity (TEEB) Ecosystem Services. Value network maps and Venn diagrams were created to explore the strength of linkages across and between values for each country. This study did not collect demographic information. Although demographic data is important, this initial collection of information was aimed at identifying values and worth rather than examining demographic attributes of the respondent's that may have influenced their perceptions.

We created simple 4-node "Value Networks" for each country to depict the relationships between the four value sets (nodes) of environmental, economic, social, and cultural and the relationships between them based on shared sub-elements (edges). The size of nodes is determined by the number of identified sub-elements aligned to that value set and the thickness of the edges represent the number of shared sub-elements (e.g., Figure 3). Value color coding aligns with Figure 2. Note that the lines to the outside of the diagram link three or all four nodes.

Elicited Values were coded into The Economics of Ecosystems and Biodiversity (TEEB) Ecosystem Services framework. Values were not restricted to a single Ecosystem Service assignation and could be coded to multiple Ecosystem Services, or where appropriate remain un-coded. We report against 17 TEEB Ecosystem Service categories, as well as the four domains of Provisioning, Regulating, Supporting, and Cultural services.

Within this research we did not investigate confidence, map uncertainty, or create uncertainty topologies (e.g., Knol et al., 2010). These facets were not undertaken because of the complexity and subjectivity of these issues, as indicated in preliminary studies, created incertitude (i.e., instability or uncertainty) across the sampling frame. Exploring respondents' confidence in responses and uncertainty also led to a sense of unease for many participants, and hence to meet ethics requirements this line of inquiry was not progressed.

\section{RESULTS}

\section{Identified Values}

A total of 337 value sub-elements, from 61 participants, were identified across environmental, economic, social, and cultural values, and combinations of these values (i.e., where a concept could be attributed to multiple values) (Figure 2). Supplementary Material (Tables $1 \mathrm{~A}-\mathrm{C}$ ) provide a breakdown of the individual values, how they relate to each of the four core values (environmental, economic, social, and cultural), and whether the perceived worth of each value sub-element increased, remained neutral or decreased after an introduction of a NMS in a specific 


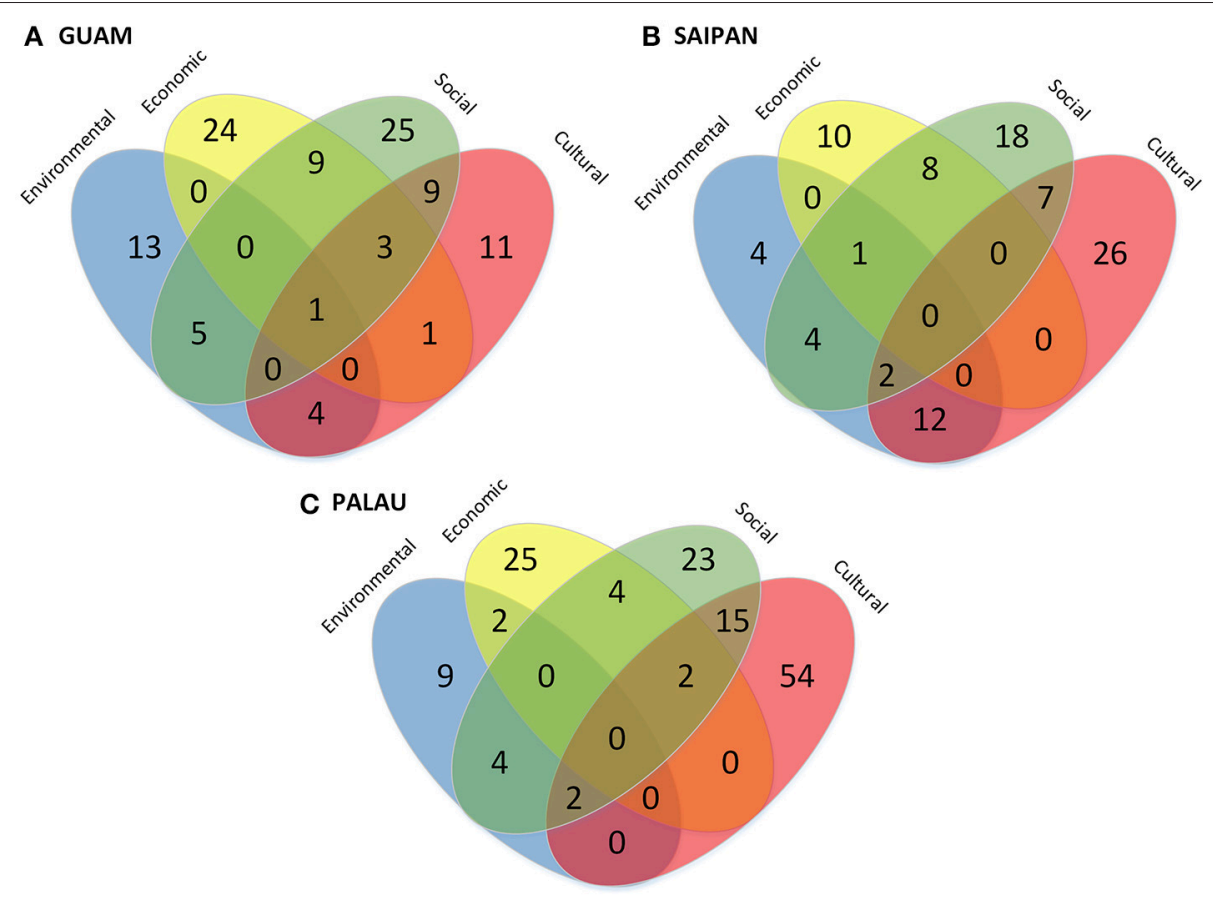

FIGURE 2 | Venn diagrams illustrating the number of respondent identified values for: (A) Guam; (B) Saipan; and (C) Palau. Overlaps indicate value sub-elements that were shared across groupings.

country. Where applicable, a range of change was used to indicate where opinions differed. We identified 140 value sub-elements for Palau, followed by 105 for Guam and then 92 for Saipan.

Guam identified the most environmental value sub-elements, followed by Palau and then Saipan (Figure 2). Palau, closely followed by Guam identified the highest number of economic value sub-elements, with a similar trend for the social value sub-elements. Palau, then Saipan identified the most cultural value sub-elements, with a large reduction in the identification of cultural value sub-elements occurring in Guam (Figure 2).

\section{Value Networks}

Value networks were created to illustrate the strength of connection across and between the values (environmental, economic, social and cultural) (Figure 3). Within Guam, there was minimal overlap or sharing between values, with most sub-element values representing just one value and relatively little participant perceived sharing of sub-elements (Figures 2A, 3A, Supplementary Material Table 1A). The values identified in Guam had strong social and economic foci (Figures 2A, 3A). Guam was the only country to identify sub-elements that were shared across five value combinations (Figure 3A). However, participants did not perceive any sharing of sub-elements between environmental and economic values (Figures 2A, 3A, Supplementary Material Table 1A).

Saipan's trends (Figures 2B, 3B, Supplementary Material Table 1B) showed weak to moderate linkages, with the cultural and environmental networks predominating (Figures 2B, 3B). Saipan identified more cultural sub-elements than other value sub-elements, yet fewer social sub-elements were identified compared with Guam, or Palau (Figure 3). Sharing of subelements existed between social and cultural values, social and economic values, and social and environmental values. There was a lack of connection between environmental and economic values, and economic and cultural values.

In Palau, there was a stronger network of sub-elements shared across values, with social and cultural values sharing the strongest linkages. Yet, in Palau there were fewer (i.e., 3) perceived cross-over of values than that identified in Guam (Figures 2C, 3C, Supplementary Material Tables 1A,B). Cultural values were more commonly identified in Palau, than in Guam or Saipan (Figure 3). A small proportion of sharing of sub-elements occurred between social and economic values, and social and environmental values. Cultural values did not share sub-elements with economic or environmental values (Figures 2C, 3C). Both Palau and Saipan lacked the connection between economic and cultural values (Figures 2, 3, Supplementary Material Tables 1B,C).

\section{Worth of Values}

Although elicitation occurred in Palau, no respondents provided opinions for the "worth of values" assessment. Hence, the data from Palau was excluded from the "worth of values" and change in worth analysis. The potential reasoning for a lack of response from Palauan participants is addressed within the discussion.

The survey (questionnaire) results had low response rates in Guam and Saipan, and as such represent a preliminary 


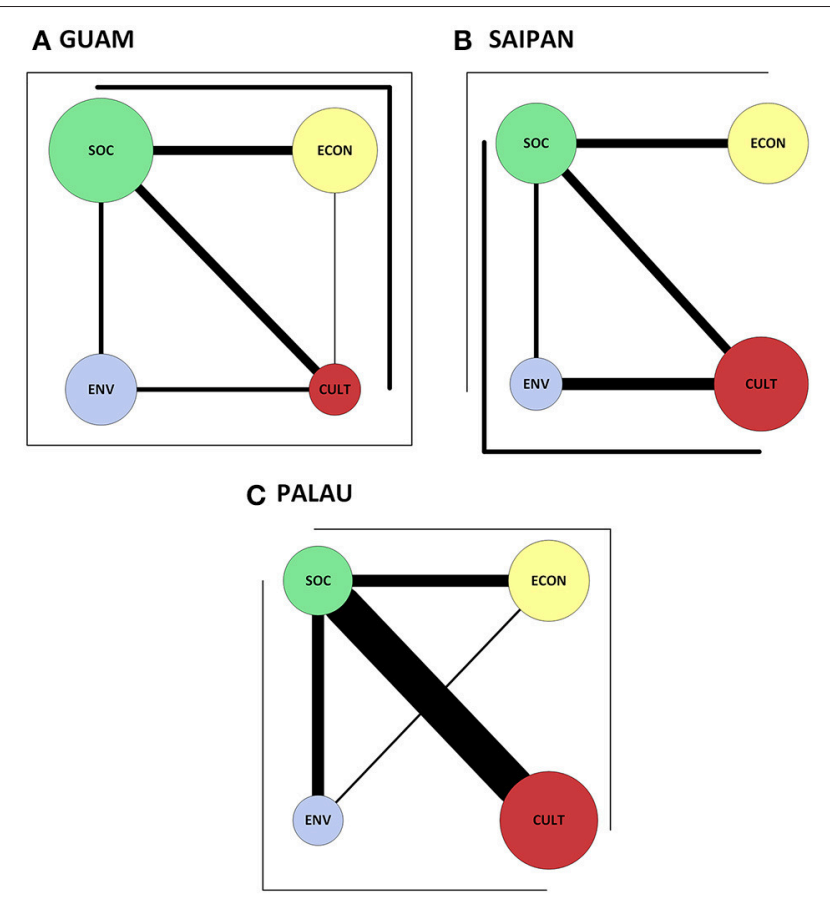

FIGURE 3 | Value networks illustrating the proportion of core values for each country and the strength of linkages between core values for: (A) Guam; (B) Saipan; and (C) Palau. Core values are denoted by SOC, social; ECON, economic; ENV, environmental; and CULT, cultural. The number of identified sub-elements in each category (one, two, three, four core values) is represented graphically by the size of the nodes or thickness of the edges (networks). Note that edges connecting three or four nodes are depicted by the outside (unconnected) lines.

exploration of value worth and change in worth. Thus, the questionnaire findings discussed below were interpreted in the context of low reliability. As a preliminary exploration we feel that the data is still promising, with some potential trends evident that need further investigation.

In Guam, survey respondents rated $60 \%$ of identified values as having medium-high or high value, with $23 \%$ having a medium value (3), and the remaining $17 \%$ having a low or low-medium value (Supplementary Material Table 1A). In general, most identified values were considered to have a medium-high or high worth, with $70 \%$ of environmental values rated as medium-high or high value, followed by $56 \%$ of social values, $54 \%$ of economic, and $27 \%$ of cultural values (Figure 4A). Economic and cultural values had a greater proportion of medium value (38 and $27 \%$, respectively; Figure 4A).

In Saipan, $76 \%$ of the identified values were rated as having medium-high or high value, with $15 \%$ having medium value and $9 \%$ having low or low-medium value (Figure 4B, Supplementary Material Table 1B). Within a value context, 91\% of environmental values were rated as medium-high or high, with $72 \%$ of economic, $96 \%$ of social and $50 \%$ of cultural values also rated as medium-high or high. Saipan participants rated a large proportion (32\%) of cultural values as having medium value (Figure 4B). Saipan respondent's also indicated

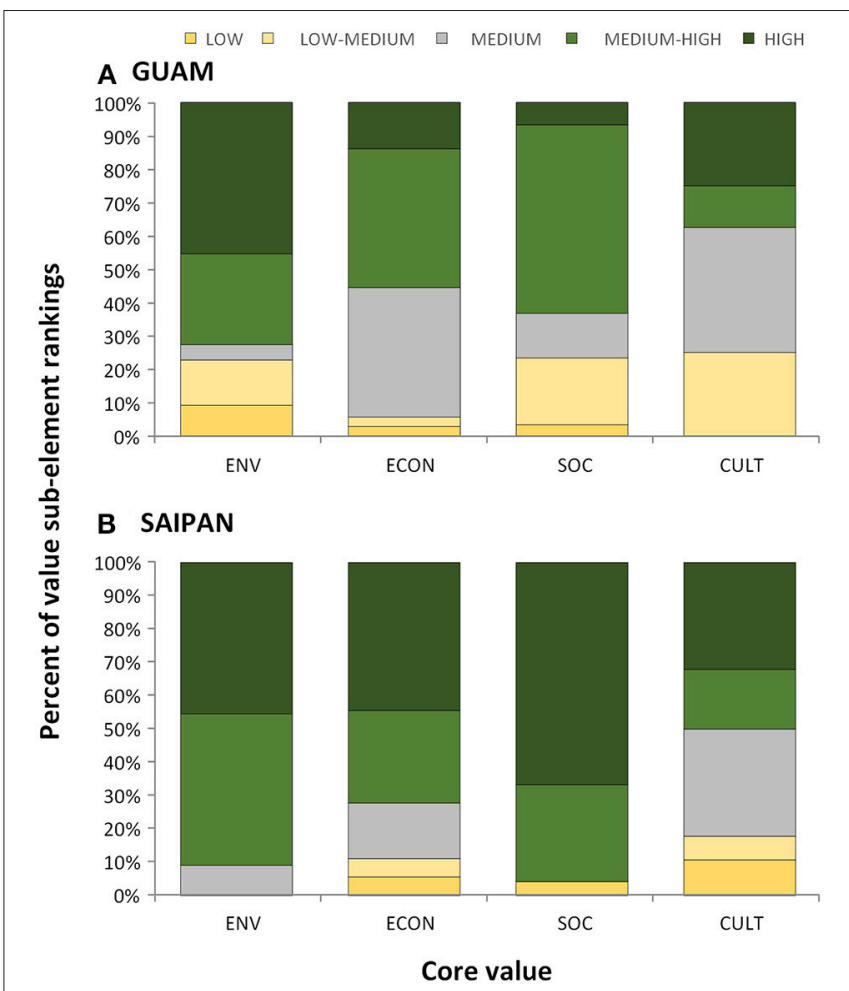

FIGURE 4 | Percentage of each core value subcomponent that was rated as having a high, moderate or low value by survey respondents for: (A) Guam; and (B) Saipan. Where values are denoted as ENV, environmental; ECON, economic; SOC, social; and CULT, cultural.

that no environmental values were considered to be low in worth (Figure 4B).

When comparing between Guam and Saipan, the largest dichotomy of perceived worth for values was observed for cultural values (Figure 4). Guam respondents ranked cultural worth as high for $54 \%$ of the identified values compared to $21 \%$ of the identified cultural values identified as high worth by Saipan respondents. Economic values were considered to have moderate worth in both countries (57\% in Guam and 59\% in Saipan; Figure 4). In Guam, respondents more commonly identified environmental values as having a higher worth than respondents' in Saipan (Figure 4), although respondents in both countries considered most identified environmental values to have high worth (74\% in Guam and 64\% in Saipan; Figure 4). A similar trend was observed for social values in Guam and Saipan, with Saipan respondents identifying slightly more social values as having high worth (64\% in Guam and $72 \%$ in Saipan). It's important to note that the identified values that were explored for worth differed between countries, and hence trends are generalized to the concept of the overarching value not the sub-elements that contributed to creating the value.

\section{Change in Value Worth}

The respondent's perceived change in worth of the identified core values could occur if a NMS arrived in their location, 
with these perceptions of change in worth varying between Guam and Saipan. Guam respondents, felt that when challenged with an NMS' arrival 57\% of the identified values worth would remain unchanged, with $39 \%$ of values perceived as having decreased worth (Figure 5A, Supplementary Material Table 1A). All values had a proportion of sub-elements that respondents felt would remain unchanged. Cultural values had the smallest proportion (24\%) of identified sub-elements that would remain unchanged, followed by environmental (57\%), social (60\%), and economic sub-elements (79\%).

No environmental or economic sub-elements were perceived as benefitting (increasing in worth) from the arrival of a NMS. However, $7 \%$ of cultural and $4 \%$ of social sub-elements were thought to increase in worth (Figure 5A, Supplementary Material Table 1A). Cultural sub-elements perceived as benefitting from a NMS arrival included "seasonal fisheries: impediment to equipment" and "food gathering: eels and shrimp." Social subelements perceived to benefit from an NMS arrival focussed on "education-University of Guam" and "education-schools" (this was expressed as the use of NMS for environmental education). The largest perceived impact (decrease in value worth) occurred for the cultural sub-elements (69\%), followed by social (37\%), environmental (43\%), and economic (21\%) subelements (Figure 5A).

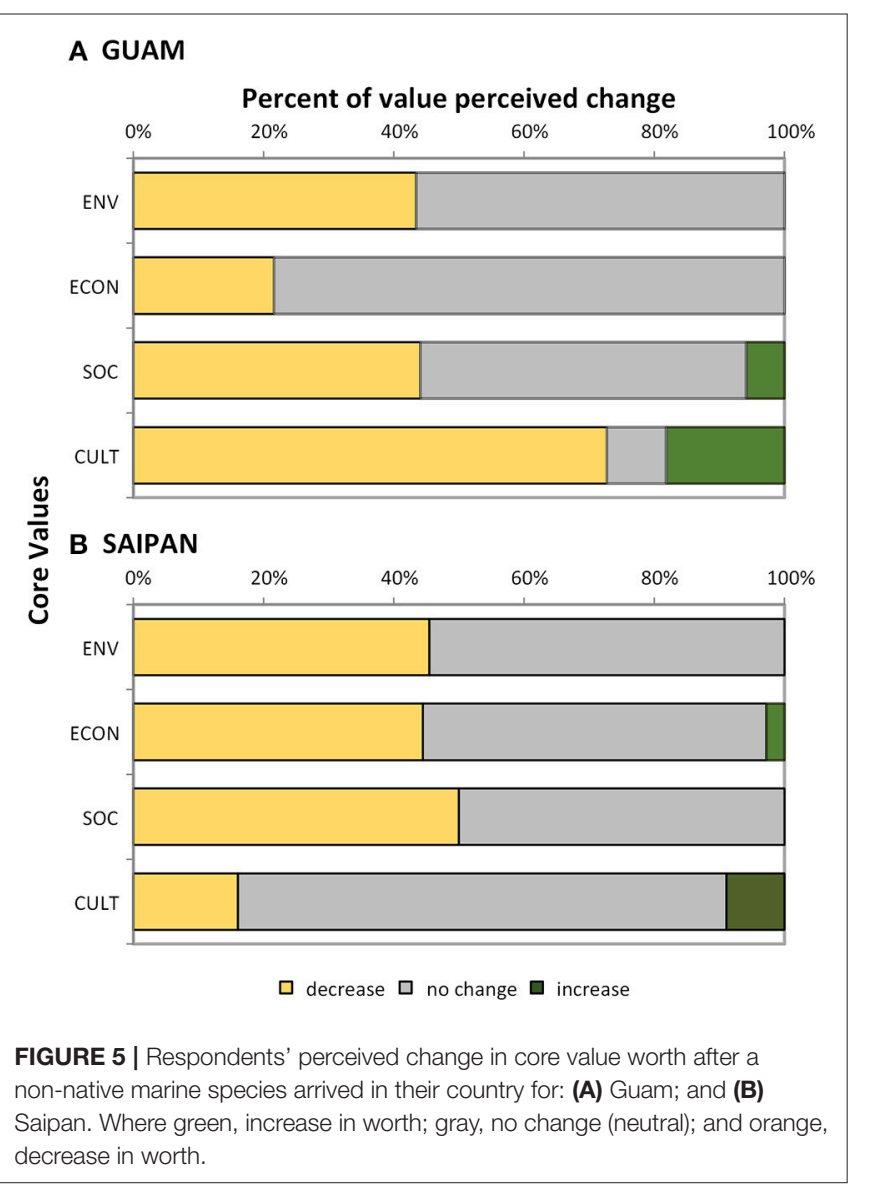

The change in worth also varied across identified values in Saipan (Figure 5B, Supplementary Material Table 1B). When challenged with a NMS arrival scenario, Saipan respondents felt that in general $57 \%$ of the values would remain unaffected. A focus on individual sub-elements identified that for environmental, economic and social sub-elements just over half of the identified sub-elements were thought to remain unaffected (Figure 5B). A large proportion (65\%) of cultural sub-elements were perceived to remain unaffected (Figure 5B).

No environmental or social sub-elements were perceived to increase in worth when challenged with a NMS arrival scenario in Saipan. Yet, 3\% of economic and 1\% of cultural sub-elements were perceived as benefitting from an NMS arrival (Figure 5B). The sub-elements that would benefit were focussed on "maintenance of historic sites via the removal of pests" (Supplementary Material Table 1B; note that Saipan has extensive World War II historic artifacts on the reef and marine environment). The smallest number of identified sub-elements that were perceived to be impacted (decrease in value worth) occurred for cultural values (35\%), followed by economic (46\%), social (47\%), and environmental (48\%) values (Figure 5B). Cultural sub-elements had the largest dichotomy of change in worth, with $65 \%$ of values remaining unchanged, and 35\% decreasing in worth (Figure 5B).

\section{Respondent Feedback}

Feedback from respondents is summarized in Table 1. We have included the respondent's feedback here as they provide important aspects and insight into how connected the public in these countries are to the sea and to their values. However, we note that a number of respondents wished to remain anonymous and provided verbal information but requested that this information not be repeated within the publication. We have respected these wishes and used the anonymous comments to inform our interpretations and discussion only. Please note that the feedback and comments are the participants' opinions only, and do not reflect the opinions of the authors.

\section{Value Assignments to Ecosystem Services}

Most of the 337 elicited values (Guam $=105$; Palau $=140$; and Saipan $=92$ ) readily translate to The Economics of Ecosystems and Biodiversity (TEEB) Ecosystem Services (ES) framework, however $24(21.0 \%)$ of the elicited values in Guam could not be coded into this framework, contrasted with 7.1\% (10) uncoded values in Palau and 10.9\% (10) in Saipan (Table 2, Figure 6). The uncoded values were largely associated with Economic and Social Core Values such as World War II tourism, Department of Defense deployment, Port traffic flow, Joint defense force exercises, and cost of maintenance for boats and infrastructure (see Supplementary Material).

Across all three localities the greatest proportion of elicited values aligned to Cultural TEEB ES, (Table 2 and Figure 6). Guam exhibited a smaller proportion of elicited values aligned to Provisioning TEEB ES, and a greater proportion of Regulating and Supporting TEEB ES, than Palau and Saipan (Table 2 and Figure 6). 
TABLE 1 | Respondent's feedback and comments.

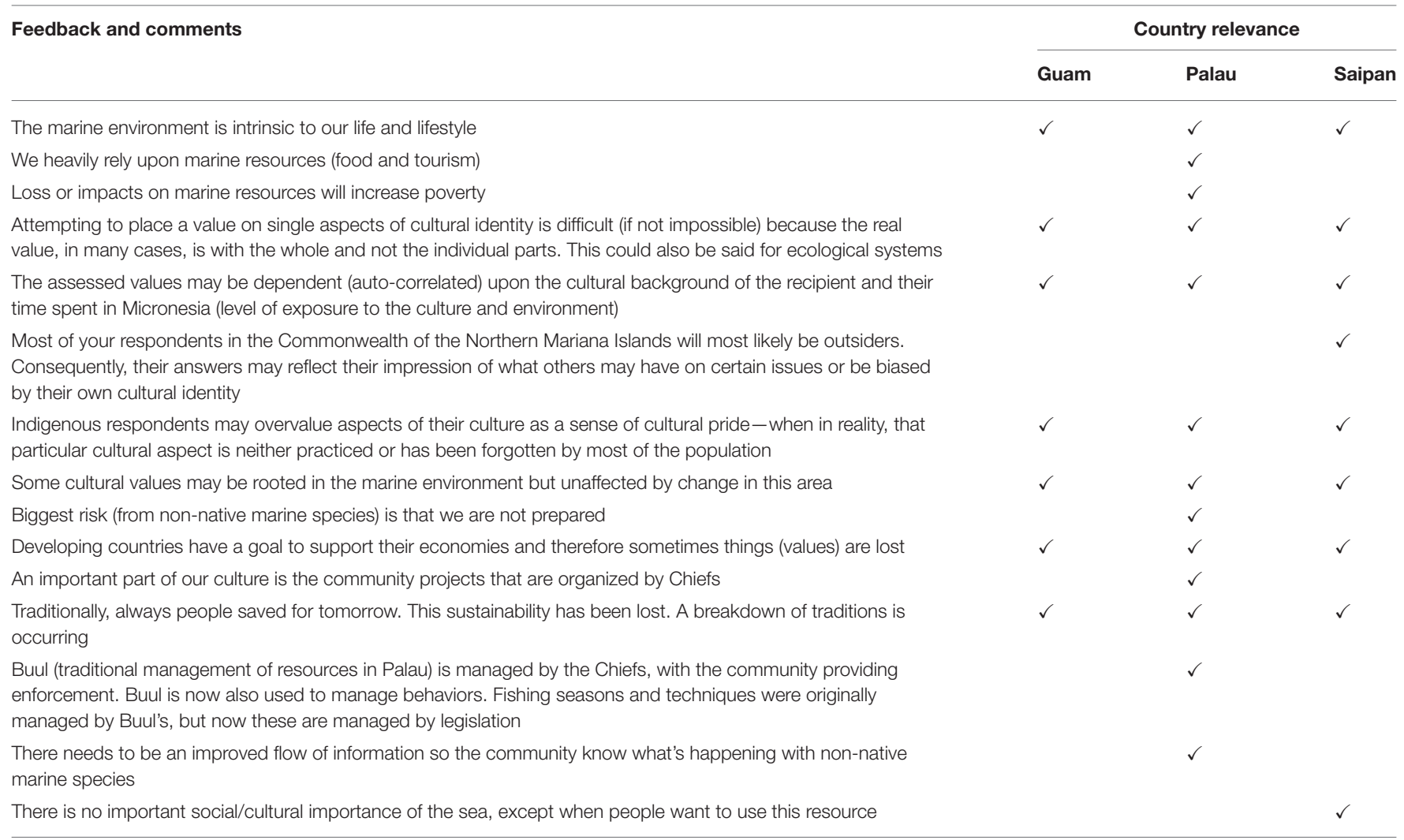

\section{DISCUSSION AND CONCLUSIONS}

The overarching aim of our research is to improve how people manage non-indigenous marine species, particularly in different socio-cultural contexts. How NMS are perceived in social and cultural contexts will heavily influence biosecurity decision making, which ultimately influences how we react to a NMS introduction. This study focussed on identifying values that could be affected by NMS and to determine if perceptions of the identified values' worth is altered if a NMS were to arrive in a country (Guam, Palau, Saipan). We identified a large number of values (total $=337$ : Guam $=105$; Palau $=$ 140; and Saipan $=92$; Supplementary Material, Tables 1A-C) for the three Micronesian localities. These values ranged across Environmental, Economic, Social, and Cultural categories, and combinations thereof (Figure 2). As to be expected, identified values varied between localities, with place-culture typically noted as having the greatest influence on spatial and temporal patterns of values (e.g., Williams, 1981).

The identification of values in this research exceeds identified values from similar biosecurity studies. For example, our previous work in New Zealand identified 11 values specifically associated with the NMS kelp, Undaria pinnatifida (Campbell and Hewitt, 2013). The current research moved beyond the use of only researchers/scientists in the elicitation processes. We believe that broader inclusion of people from different disciplines (beyond science and research) in the elicitation process has resulted in a greater number of value sub-elements being identified. Similarly Campbell (2008) used stakeholder and public focal group interviews to examine the potential impact of the non-native freshwater diatom Didymosphenia geminata. Stakeholders (including scientists and researchers) and public focal groups identified 73 values that could be impacted by the D. geminata introduction (Campbell, 2008). The elicitation process used in this and the D. geminata studies combined scientists, researchers and interested stakeholder groups (that ranged across government officials, industry and the public), and clearly identified more values than previous studies. The inclusions of opinions beyond those of "experts" (researchers and scientists) benefitted this research as more values were identified than previous marine biosecurity research.

The focus topic (marine biosecurity) was also topical at the time of the research, which led to a good level of engagement across the community. We recommend that this inclusive elicitation approach should form the basis of a biosecurity decision support tool by illustrating the public's valid concerns.

During this study it became evident that American imperialism (i.e., Zimmerman, 1998) has potentially influenced the values identified and reported for Guam and Saipan. Yet, the American influence in Palau appears to be less intense. We note that Palau is a Republic that was once a US Protectorate (and previously Japanese Territory) but has now attained independent governance. We believe that these differences in American 


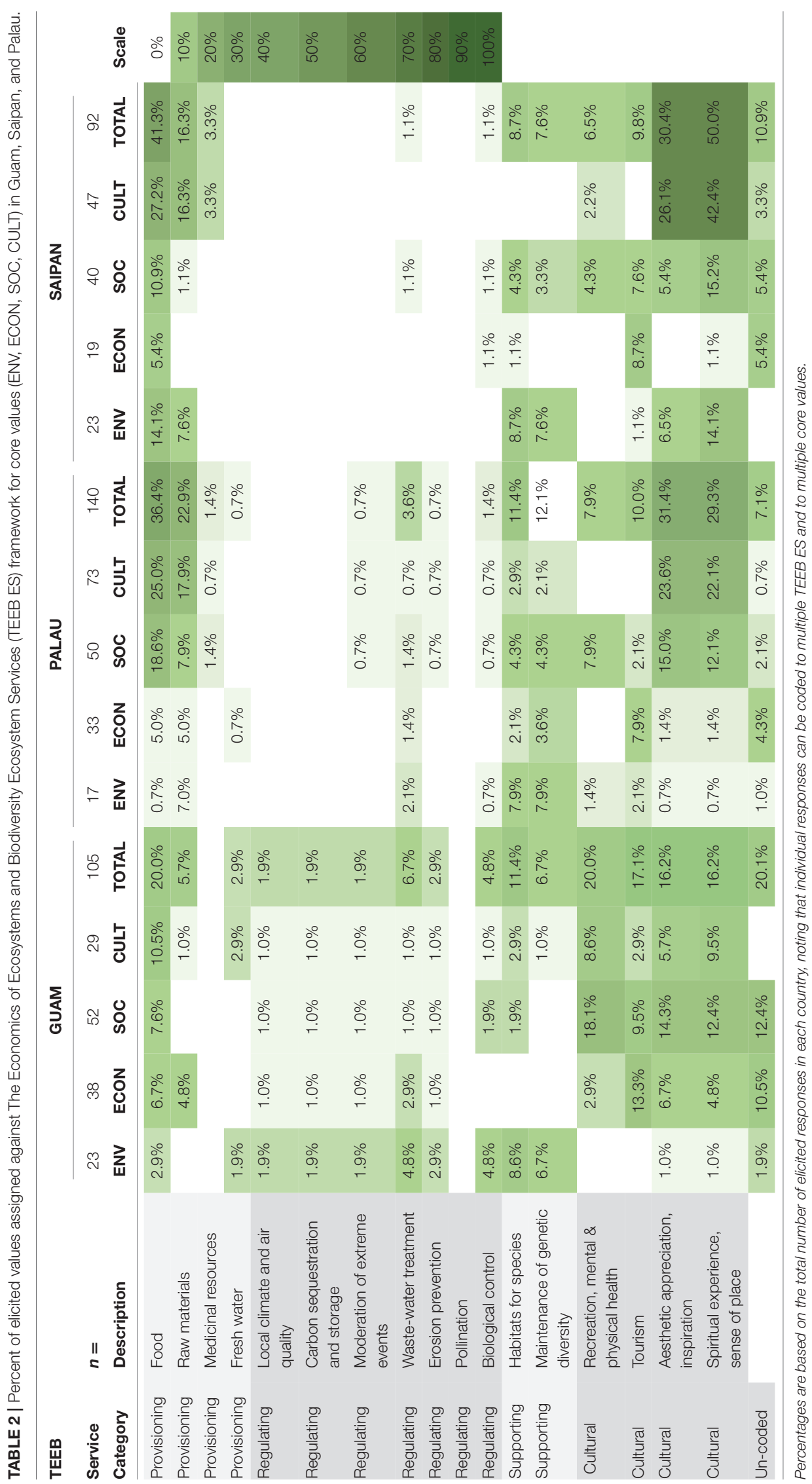




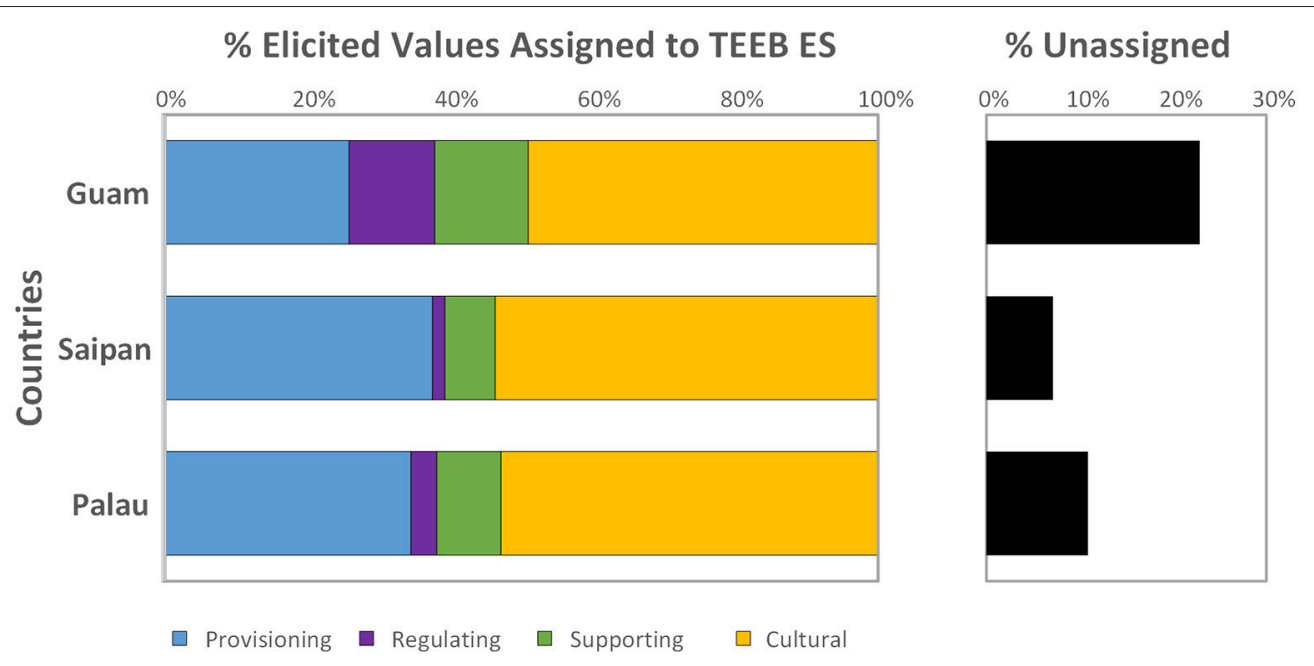

FIGURE 6 | Alignment of values with The Economics of Ecosystems and Biodiversity Ecosystem Services (TEEB ES) framework. Note that unassigned values are percentages of the total number of values, whereas assigned values are percentages of total assigned values.

influence are reflected by the higher number of identified cultural values and the strength of network connections between cultural and other values in Palau. We discuss our findings further below, noting that the information gathered is important for analysis of risk and potential biosecurity management activities that flow from derived risk. However, further exploration of the social trends occurring and the potential demographic influences to responses for individual countries is needed to provide more in-depth insight that we cannot provide within this preliminary study.

\section{Value Networks Guam}

Environmental and cultural values exist in Guam but were not valued as highly as economic and social values. Connections were shared between multiple values, with the exception of environmental and economic values (Figure 3A). All connections were weak to moderate with no strong connections between or across values. Furthermore, participants identified significantly fewer cultural values than environmental, economic or social values (Figure 3A). This lack of strong connection and identification of cultural values may be related to the history of this region. Guam has had a long history of being occupied by foreign nations (including occupation by the Spanish, Japanese and Americans), which has resulted in the loss of the Chamorro culture (JennisonNolan, 1979a,b; Diaz, 1994; Rogers, 1995; Zimmerman, 1998). Guam is currently a US Territory, with a large US military presence.

The stronger prevalence of the participants to identify social and economic values could indicate a predisposition toward utilitarian societal norms. Guam is heavily influenced by the US and subsequently the resource conservation ethic (i.e., natural resources abound in nature and should be used, with conservation standing for development; Pinchot, 1947; Callicott,
1990). The resource conservation ethic is strongly ensconced in the US legislation and government management of resources (Callicott, 1990; Groom et al., 2006) and, as a US Territory in the Pacific, local norms and beliefs are often perceived as being diluted as American laws and practices are adopted. This pattern is often referred to as "peripheralization" (Wilson, 2000; Perez, 2002), where there is a "differential distribution of power, interest, labor, and capital across space, and the domination of local spaces and cultures by the mandates of military-industrial time" (Wilson, 2000).

We found a strong indication by participants that they felt that Guam was disenfranchised, resulting in a loss of culture through "Americanization" (e.g., Barusch and Spaulding, 1989; Diaz, 1994; Perez, 2002). This was reinforced by participant responses indicating that they did not want more US Defense Corps Forces in Guam. This was further demonstrated by street protests that have occurred, both during the survey work and subsequently (e.g., http://ww4report.com/node/8160; http://links.org.au/node/1547; http://reefrescue.wordpress.com/ 2010/02/26/guam-protests-navys-plan-to-dredge-coral-reef/; http://www.horseopera.org/Insular_Empire_2010/?page_id= 564).

There was also a general perception amongst some participants that cultural values are no longer authentic because they are not practiced by the majority of the population (Table 1), or that modern society has no room for these "outdated" concepts. However, typically these sentiments were provided by Caucasian expatriate Americans, not self-identified Chamorro or Carolinian participants.

The alignment of elicited values to TEEB ES framework supports the increased modernisation of societal norms with a shift of focus from Provisioning ES, and a greater focus on Regulating ES. The importance of Cultural ES such as Recreation and human wellbeing, and Tourism are higher in Guam than in either Palau or Saipan. 


\section{Palau}

Cultural values, followed by economic, social and then environmental values were identified in Palau (Figure 3C). The strongest of network connections occurred between social and cultural values, which might be driven by the strong community and cultural identity that remains in Palau. Palau also has a strong cultural law referred to as "Buul." The Buul is a recognized and traditional conservation regulation system (Nichols, 1991; D Olkeriil pers. comm.). Buul is used to govern usage of species, ecosystems, and fishing grounds (e.g., Johannes, 1978, 2002), and influences lifestyles, including environmental goals aligned with conservation (D. Olkeriil pers. comm.). At the time of this research, the Palauan parliament was working on translating traditional stewardship into legislation that simplifies the three tiered system that currently exists (N. Idechong and D. Alexander pers. comm.).

Marine protection has a strong focus within Palau (e.g., Gilman, 1997a), especially within tourist focal areas such as the Rock Islands, Koror, or on specific species that have cultural value (e.g., Campbell, 2003; I. Olkeriil pers. comm.). This protection stance is often linked with customary management of marine resources (Gilman, 1997a; Johannes, 2002; D. Olkeriil and I. Olkeriil pers. comm.) that have been degraded in the past but are being rebuilt at present (N. Idechong and D. Alexander pers. comm.). Palau has established a team of marine biosecurity park rangers that are capable of identifying and dealing with introductions of NMS (Campbell et al., 2016).

Identified values in Palau are strongly aligned to Provisioning ES and Cultural ES, with specific elements of Provision of food and raw materials, and Cultural ES associated with Aesthetic and Spiritual experiences.

\section{Saipan}

The number of value sub-elements identified for Saipan was similar to Palau (see below), with a large number of cultural value sub-elements, followed by an equal weighting of social and economic value sub-elements, but fewer environmental value sub-elements (Figure 3B). Of importance to note is that within Saipan, the importance of the sea turtle has been used to express and maintain Carolinian culture (Kolinski et al., 2001). This particular sub-element worth was identified by participants as high. Much like Guam, the connections between values were relatively weak, with the strongest connection existing between environmental and cultural values.

It is likely that the history of Saipan has had an influence on the identified values, assessed worth, and changes in worth. Saipan has had five centuries of colonial rule, seen four empires, and accommodates two indigenous cultures (RiosMartinez, 2000). Chamorro's were forcibly removed from Saipan for a significant portion of the island's history, with the Carolinian culture becoming dominant during this period. When the Chamorro people returned to Saipan, a disjunction in their Saipan culture had been created ( $R$. Hunter pers. comm.).

Saipan is one of the countries in the US Commonwealth of the Northern Mariana Islands (CNMI) that became a
Commonwealth of the US in 1986 (Gilman, 1997b; RiosMartinez, 2000). Subsequently, Saipan has become heavily influenced by the US (Rios-Martinez, 2000; Warheit, 2010; Oldenziel, 2011). The form of US colonialism that exists in Saipan is one where a number of "insular areas" are occupied by the US, where the CNMI countries are provided with some political oversight, but have fewer rights than a sovereign nation (King, 1991; Rios-Martinez, 2000; Warheit, 2010; Oldenziel, 2011). For example, a number of elements of sovereignty were surrendered when Saipan and the US formed the Commonwealth (King, 1991; Rios-Martinez, 2000; Warheit, 2010), with a major issue being the loss of the Islands' rights to self-governance. This loss of power has caused some issues through time in both Saipan and Guam, where residents are perceived as second class citizens because they live in countries that are vital to US military network hubs (Oldenziel, 2011).

Much like Palau, identified values in Saipan are strongly aligned to Provisioning ES and Cultural ES, with specific elements of Provision of food, and Cultural ES associated with Aesthetic and Spiritual experiences.

\section{Worth and Changing Values A Valid Approach?}

We undertook the NMS arrival and subsequent impact scenario testing using an online questionnaire. This approach provided some data, but was not an effective method to collect data in these locations, most likely due to cultural norms, where face to face interactions and submersion in the culture would have been a preferred data collection method. However, the data collected is presented as it does provide some valuable insights. We applied an axiomatic approach by determining identified values for a region, and then described a relevant scenario that could cause change (i.e., the introduction of a NMS). Capturing likely and/or perceived changes using scenarios has become a common method for climate change (e.g., Cheung et al., 2009), transport (Geurs and Ritsema van Eck, 2001) and cumulative effects (Duinker et al., 2012) analyses, for example. With this approach we were able to capture perceptions of change in Guam and Saipan but not for Palau (Figure 5).

The methods we employed did not use Willingness to Pay (WTP) and Willingness to Accept (WTA) style assessment methods, or rely on dollar based systems that are commonly used (e.g., Knetsch, 1994; Satterfield, 2001; Emerton and Bos, 2004; IUCN/The Nature Conservancy/The World Bank, 2004; Pagiola et al., 2004; The World Bank, 2004; Kalof and Satterfield, 2005). Instead, our elicitation technique used a narrative (via interviews, group discussions, literature and museum searches, and surveys) to collect and/or identify values for each country and gauge worth and change in worth against these values via scenario testing. The central question that we investigated was "what were the values that would be affected by an introduction of a NMS?" The foundation of this method is that data collection is driven by participants that are local to the countries being examined (i.e., not influenced by outside observer preferences). This method has been suggested as ideal 
for identifying and capturing the worth of values when nonmarket based values are explored (Satterfield, 2001). Thus, our approach was sound, but we required more time in country to fully explore the scenarios using a face-to-face elicitation method that was more suitable to the countries sampled.

The poor response rate to the online questionnaire in Palau needs further consideration. A complete lack of responses could suggest poor buy-in of participants to the questionnaire, however this attitude was not evident within the interviews and discussions that had elicited keen interest, with people expressing a desire for inclusion. Within Palau, freedom of enquiry is restricted in some instances, which may have resulted in the poor online survey response rate. For example, Kesolei (1977) discusses the concept that Palauan's believe that there is a hierarchy to data availability. Full information disclosure to the public is rare. In a social context, the more you know in Palauan society the more credibility you are afforded, where information flow (or the right to know) is based on an individual's social status, age, or lineage (Gilman, 1997b). Thus, requesting participants to state their perception of a value's (or the sub-element's) worth and potential change may have crossed social boundaries, resulting in nonparticipation.

We also note that across all three countries a tendency toward the medium option was apparent, though not overly represented for most values. In Guam, $23 \%$ of respondents identified all value worth as medium, with $38 \%$ of economic values and $27 \%$ of cultural values listed as medium. In Saipan, $15 \%$ of respondents identified all value worth as medium, with $32 \%$ of cultural values and $17 \%$ of economic values listed as medium. This may reflect considered worth, however it might also indicate an inability to properly assess worth, resulting in selection of the middle option (i.e., to remain undecided).

\section{Did Worth Change?}

In general, participants from Guam and Saipan indicated that few values (1.8\%) would benefit from an NMS arrival in their country. Values thought to benefit from an NMS introduction were utilitarian with an anthropocentric focus, and included education (through the University of Guam and schools), food gathering, and maintenance of fisheries equipment and historical sites. An NMS incursion would decrease the worth of a number of values, with almost $41 \%$ of values (summed across all core values) being affected (Figure 5).

Although the study needs further validation, in a management context the "no change in worth" values $(57.1 \%)$ would be excluded from further assessment or action, as the "no change in worth" outcome infers that these values are not perceived to be deleteriously impacted by an NMS arrival. It is the values that have decreasing worth that would require management focus and potentially action if possible. For example, in Guam damage to the aquaculture market due to loss of a disease-free image were perceived as vulnerable to NMS and stricter biosecurity actions could be put in place to manage these perceived effects. However, some perceived loss of worth could be difficult to manage as actions may be too costly to implement, or effective actions may not exist. For example, effects to "sacred sites" may be difficult to manage.

\section{Future Research Needs and Recommendations}

The preliminary research presented here indicates that there is some concern over the impacts that NMS will have in Guam and Saipan. As discussed above, further exploration of Palau perceptions in light of a NMS introduction needs to occur. Hence, we strongly recommend that a full-scale perceptions study be undertaken in the Micronesian region to determine the perceptions of effect of NMS on values. Such a study would involve using the representative sample sizes from each participating country to identify values, each value's worth, and potential changes in value. Information collected needs to be in a format that would feed into an NMS risk assessment framework to enable social and cultural values to be assessed alongside economic and environmental values.

Data collection methods need to be refined to meet each countries needs and cultural requirements and to allow face-to-face interviews with a greater sample size of people. Questionnaires were not an effective tool in this instance and the reliability of the data could easily be improved by running a number of stakeholder workshops, group interviews, and interviews with individuals. In general, interviews (individual or group) provided the most valuable data, but we feel that workshops (facilitated by local or a regional agencies with expert input) may be more effective to gauge perceptions, especially with regards to the social and cultural elements of potential impact from NMS. In societies where information flow is select or restricted (e.g., Palau) there is a need to more fully engage with government agencies. This could be achieved via the use of more intensive oneon-one interviews that collect questionnaire information directly.

We note however, that because of the preliminary nature of this research it is necessary to reiterate that the outcomes are descriptive, they under-represent the population (small and non-random sample size), and hence have a low reliability. Further exploration of the perceived worth and impacts (change in worth), especially to the core values assessed here, would be valuable to provide information for decisionmakers regarding potential NMS introductions. We urge that such further research should follow an ethnographic design that enables the researchers to spend more time with the populations within Micronesia, to truly gauge the level of worth and potential change to values from the perceived effect of NMS.

\section{ETHICS STATEMENT}

Ethics approval was provided for this research (H11233) by the Tasmanian Social Science Human Research Ethics Committee. In 
all instances, we followed the approved ethics sampling methods and met the Australian National Statement standards. Informed consent was obtained from all participants. This research was unfunded but we note that it was aligned with a National Invasive Species Council and the US Defense Forces funded research project (and reported as an appendix to that research project) that examined the biological risk of non-native marine species in Guam due to the redeployment of US Defense force personnel to Guam. The National Invasive Species and the US Defense Forces had no such involvement in study design, collection, analysis and interpretation of data, writing our manuscript, or the decision to submit this article for publication.

\section{REFERENCES}

Adamowicz, W. L. (2004). What's it worth? An examination of historical trends and future directions in environmental valuation. Aust. J. Agri. Res. Econ. 48, 419-443. doi: 10.1111/j.1467-8489.2004.00258.x

Azmi, F., Primo, C., Hewitt, C. L., and Campbell, M. L. (2015). Assessing marine biosecurity risks when data are limited: bioregion pathway and species-based exposure analyses. ICES J. Mar. Sci. 72, 1078-1091. doi: 10.1093/icesjms/ fsu236

Babbie, E. (2007). The Practice of Social Research, 11th edn. Wadsworth: Thomson.

Barusch, A. S., and Spaulding, M. L. (1989). The impact of Americanization of intergenerational relations: an exploratory study on the U.S. Territory of Guam. J. Sociol. Welfare. 16, 61-79.

Callicott, J. B. (1990). Whither conservation ethics?. Conser. Biol. 4, 15-20. doi: 10.1111/j.1523-1739.1990.tb00261.x

Campbell, L. M. (2003). "Contemporary culture, use and conservation of sea turtles," in The Biology of Sea Turtles, Vol. II, eds. P. L. Lutz, J. A. Musick, and J. Wyneken (Boca Raton, FL: CRC Press), 455.

Campbell, M. L. (2008). Organism impact assessment: risk analysis for post-incursion management. ICES J. Mar. Sci. 65, 795-804. doi: 10.1093/icesjms/fsn083

Campbell, M. L., and Gallagher, C. (2007). Assessing the relative effects of fishing on the New Zealand marine environment through risk analysis. ICES J. Mar. Sci. 64, 256-270. doi: 10.1093/icesjms/fs1032

Campbell, M. L., and Hewitt, C. L. (2013). Protecting high-value areas from introduced marine species. Manag. Biol. Invas. 4, 171-182. doi: $10.3391 /$ mbi.2013.4.3.01

Campbell, M. L., Hewitt, C. L., and Miles, J. (2016). Marine pests in paradise: capacity building, awareness raising and preliminary introduced species port survey results in the Republic of Palau. Manag. Biol. Invas. 7, 351-363. doi: 10.3391/mbi.2016.7.4.05

Cheung, W. W. L., Lam, V. W. Y., Sarmiento, J. L., Kearney, K., Watson, R., and Pauly, D. (2009). Projecting global marine biodiversity impacts under climate change scenarios. Fish. Fish. 10, 235-251. doi: 10.1111/j.1467-2979.2008.00315.x

Cliff, N., and Campbell, M. L. (2012). Perception as a tool to inform aquatic biosecurity risk assessments. Aquat. Invas. 7, 387-404. doi: 10.3391/ai.2012.7.3.010

Davidson, A., Campbell, M. L., Hewitt, C. L., and Schaffelke, B. (2015). Assessing the impacts of nonindigenous marine macroalgae: an update of current knowledge. Bot. Mar. 58, 55-79. doi: 10.1515/bot-2014-0079

Diaz, S., Pascual, U., Stenseke, M., Martin-Lopez, B., Watson, R. T., Molnár, Z., et al. (2018). An inclusive approach to assess nature's contributions to people. Science 359: 270-272. doi: 10.1126/science.aap 8826

Diaz, V. M. (1994). Simply chamorro: telling tales of demise and survival in Guam. Contem. Pac. 6, 29-58.

Duinker, P. N., and Greig, L. A. (2007). Scenario analysis in environmental impact assessment: improving explorations of the future. Environ. Impact Assess. Rev. 27, 2006-2219. doi: 10.1016/j.eiar.2006.11.001

\section{AUTHOR CONTRIBUTIONS}

MC and $\mathrm{CH}$ developed and implemented the method and study described; $\mathrm{MC}$ and $\mathrm{CH}$ analyzed and interpreted the data, and wrote the manuscript text. MC prepared Figures 1, 2, 4, 5. CH prepared Figures 3, 6. All authors reviewed the manuscript.

\section{SUPPLEMENTARY MATERIAL}

The Supplementary Material for this article can be found online at: https://www.frontiersin.org/articles/10.3389/fmars. 2018.00247/full\#supplementary-material

Duinker, P. N., Burbidge, E. L., Boardley, S. R., and Grieg, L. A. (2012). Scientific dimensions of cumulative effects assessment: toward improvements in guidance for practice. Environ. Rev. 21, 40-52. doi: 10.1139/er-2012-0035

Elliott, M. (2013). The 10-tenets for integrated, successful and sustainable marine management. Mar. Pollut. Bull. 74, 1-5. doi: 10.1016/j.marpolbul.2013.08.001

Elliott, M., Cutts, N. D., and Trono, A. (2014). A typology of marine and estuarine hazards and risks as vectors of change: a review for vulnerable coasts and their management. Ocn. Coast. Manag. 93, 88-99. doi: 10.1016/j.ocecoaman.2014.03.014

Emerton, L., and Bos, E. (2004). Value. Counting Ecosystems as Water Infrastructure. Gland: IUCN.

Esterberg, K. G. (2002). Qualitative Methods in Social Research. Boston, MA: McGraw Hill.

Geurs, K. T., and Ritsema van Eck, J. R. (2001). Accessibility measures: Review and applications. Evaluation of accessibility impacts of land-use transportation scenarios, and related social and economic impact. RIVM Report 408505 006. Available online at:https://www.rivm.nl/en/Documents_ and_publications/Scientific/Reports/2001/juni/Accessibility_measures_ review_and_applications_Evaluation_of_accessibility_impacts_of_land_ use_transportation_scenarios_and_related_social_and_economic_impact?sp= $\mathrm{cml}$ bXE9ZmFsc2U7c2VhcmNoYmFzZT01NTA0MDtyaXZtcT1mYWxzZTs=\& pagenr $=5505$ (Accessed April 30, 2018).

Gilman, E. L. (1997a). Community based and multiple purpose protected areas: a model to select and manage protected areas with lessons from the Pacific Islands. Coast. Manag. 25, 59-91. doi: 10.1080/08920759709362310

Gilman, E. L. (1997b). A method to investigate wetland mitigation banking for Saipan, Commonwealth of the Northern Mariana Islands. Ocn. Coast. Manag. 34, 117-152. doi: 10.1016/S0964-5691(96)00075-0

Groom, M. J., Meffe, G. K., and Carroll, C. R. (2006). Principles of Conservation Biology. Sunderland, MA: Sinauer Associates.

Gurevitch, J., and Padilla, D. K. (2004). Are invasive species a major cause of extinctions? Trends. Ecol. Evol. 19, 470-474. doi: 10.1016/j.tree.2004.07.005

Hewitt, C. L. (2003). The diversity of likely impacts of introduced marine species in Australian waters. Rec. South Aust. Mus. Monogr. Ser. 7, 3-10.

Hewitt, C. L., Campbell, M. L., Fofonoff, P., and Minton, M. (2012). “Assessment of marine invasion risks associated with relocation of US Marine Corps Forces to Guam," in Marine Invasive Species Risk Assessment for the Commonwealth of the Northern Mariana Islands, Guam, Hawai'I, Palau, the Federated States of Micronesia, and the Republic of the Marshall Islands, Vol. 4, eds. G. M. Ruiz and C. J. Zabin (Edgewater, MD: Smithsonian Environmental Research Center), 143-312. Available online at: http://guaminsects.net/anr/sites/default/files/ Regional\%20Biosecurity\%20Plan\%20for\%20Micronesia\%20and\%20Hawaii \%20Volume\%20III.pdf (Accessed April 30, 2018).

Huan, I. B., Keisler, J., and Linkov, I. (2011). Multi-criteria decision analysis in environmental sciences: ten years of applications and trends. Sci. Tot. Environ. 409, 3578-3594. doi: 10.1016/j.scitotenv.2011.06.022

Huxel, G. R. (1999). Rapid displacement of native species by invasive species: effects of hybridization. Biol. Conser. 89, 143-152. doi: 10.1016/S0006-3207(98)00153-0 
IUCN/The Nature Conservancy/The World Bank (2004). How much is an Ecosystem worth? Assessing the Economic Value of Conservation. Washington, DC: The International Bank for Reconstruction and Development/The World Bank.

Jay, M., and Morad, M. (2006). The socioeconomic dimensions $\mathrm{f}$ biosecurity: the New Zealand experience. Int. J. Environ. Stud. 63, 293-302. doi: 10.1080/ 00207230600773125

Jennison-Nolan, J. (1979a). Guam: Changing Patterns of Coastal Marine Exploitation. Agana: SeaGrant Publication UGSG.

Jennison-Nolan, J. (1979b). Land and Lagoon use In prewar Guam: Agat, Piti, and Asan. MARC Working Papers \# 15, Micronesian Area Research Center, University of Guam.

Johannes, R. E. (1978). Traditional marine conservation methods in Oceania and their demise. Ann. Rev. Ecol. Syst. 9, 349-364. doi: 10.1146/annurev.es.09.110178.002025

Johannes, R. E. (2002). The renaissance of community-based marine resource management in Oceania. Ann. Rev. Ecol. Syst. 33, 317-340. doi: 10.1146/annurev.ecolsys.33.010802.150524

Kalof, L., and Satterfield, T. (2005). Environmental Values. London: Earthscan.

Kempton, W. (1991). Lay perspectives on global climate change. Glob. Environ. Change 1, 183-208. doi: 10.1016/0959-3780(91)90042-R

Kesolei, K. (1977). "Restrictions to freedom of inquiry: Palauan strains," in Workshop on the Role of Anthropology in Contemporary Micronesia (TTPI) (Agana), 1-12.

King, V. (1991). The Commonwealth of the Northern Mariana Islands' rights under United States and international law to control its exclusive economic zone. Univ. Hawaii Law Rev. 13, 477-504.

Knetsch, J. L. (1994). Environmental valuation: some problems of wrong questions and misleading answers. Environ. Val. 3, 351-368. doi: $10.3197 / 096327194776679629$

Knol, A. B., Slottje, P., van der Sluijs, J. P., and Lebret, E. (2010). The use of expert elicitation in environmental health assessment: a seven step procedure. Environ. Heal. 9:19. doi: 10.1186/1476-069X-9-19

Kolinski, S. P., Parker, D. M., Ilo, L. I., and Ruak, J. K. (2001). An assessment of the sea turtle and their marine and terrestrial habitats at Saipan, Commonwealth of the Northern Mariana Islands. Micronesica 34, 55-72.

Lui, S., Sheppard, A., Kriticos, D., and Cook, D. (2011). Incorporating uncertainty and social values in managing invasive alien species: a deliberative multi-criteria evaluation approach. Biol. Invasions 13, 2323-2337. doi: 10.1007/s10530-011-0045-4

Munda, G., Nijkamp, P., and Rietveld, P. (1994). Qualitative multicriteria evaluation for environmental management. Ecol. Econ. 10, 97-112. doi: 10.1016/0921-8009(94)900002-7

Nichols, P. V. (1991). Republic of Palau: Marine Resources Profiles. FFA Report No. 91/59. Honiara: Fisheries Development Section, Forum Fisheries Agency.

Ojaveer, H., Galil, B. S., Campbell, M. L., Carlton, J. T., Canning Clode, J., Cook, E., et al. (2015). Classification of non-indigenous species based on their impacts: the marine perspective. PLoS Biol. 13:e1002130. doi: 10.1371/journal.pbio. 1002130

Oldenziel, R. (2011). "The Islands: The United States as a networked empire," in Entangled Geographies. Empire and technopolitics in the Global Cold War, ed G. Hecht (London: MIT Press), 13-42.

Pagiola, S., von Ritter, K., and Bishop, J. (2004). Assessing the Economic Value of Ecosystem Conservation. Environmental Department Papers. Paper No. 101. (Washington, DC: The World Bank), 57.

Perez, M. P. (2002). Pacific identities beyond US racial formations: the case of Chamorro ambivalence and flux. Soc. Iden. 8, 457-479. doi: 10.1080/1350463022000030001

Pinchot, G. (1947). Breaking New Ground. Harcourt, NY: Island Press, 522.

Proctor, W., and Drechsler, M. (2006). Deliberative multicriteria evaluation. Environ. Plan. C 24, 169-190. doi: 10.1068/c22s

Regan, H. M., Colyan, M., and Burgman, M. A. (2002). A taxonomy and treatment of uncertainty for ecology and conservation biology. Ecol. Appl. 12, 618-628. doi: 10.1890/1051-0761(2002)012[0618:ATATOU] 2.0. $\mathrm{CO} ; 2$
Reser, J. P., and Bentrupperbäumer, J. M. (2005). What and where are environmental values? Assessing the impacts of current diversity of use of "environmental" and "World Heritage" values. J. Environ. Psychol. 25, 125-146. doi: 10.1016/j.jenvp.2005.03.002

Rios-Martinez, M. (2000). Congressional colonialism in the Pacific: The case of the Northern Mariana Islands and its covenant with the United States. Scholar 3, 41-70.

Rogers, R. F. (1995). Destiny's Landfall. A History of Guam. Hawaii: University of Hawaii Press, 381.

Ruiz, G. M., Carlton, J. T., Grosholz, E. D., and Hines, H. A. (1997). Global invasions of marine and estuarine habitats by non-indigenous species: mechanisms, extent, and consequences. Am. Zool. 37, 621-632. doi: $10.1093 / \mathrm{icb} / 37.6 .621$

Ruiz, G. M., Fofonoff, P., and Hines, A. H. (1999). Non-indigenous species as stressors in estuarine and marine communities: assessing invasion impacts and interactions. Limnol. Oceanogr. 44, 950-972. doi: 10.4319/lo.1999.44.3_part_2.0950

Ruiz, R. M., and Zabin, C. J. (eds.). (2012). Marine Invasive Species Risk Assessment and Biosecurity Plan for Guam and the Micronesian Region. Report Prepared for the National Invasive Species Council by the Smithsonian Estuarine Research Centre.

Satterfield, T. (2001). In search of value literacy: suggestions for the elicitation of environmental values. Environ. Val. 20, 331-359. doi: $10.3197 / 096327101129340868$

Sheeran, P., and Orbell, S. (1999). Implementation intentions and repeated behaviour: augmenting the predictive validity of the theory of planned behaviour. Eur. J. Soc. Psychol. 29, 349-369.

Slovic, P. (1987). Perception of risk. Science 236, 280-285. doi: $10.1126 /$ science. 3563507

Slovic, P. (2000). The Perception of Risk. London: Earthscan.

The World Bank., (2004). 1988-2004 Ensuring the Future. Washington, DC: The World Bank and Biodiversity. The World Bank.

Turvey, C. G., Onyango, B., Cuite, C., and Hallman, W. K. (2010). Risk, fear, bird flu and terrorists: a study of risk perceptions and economics. J. Socio-Econ. 39, 1-10. doi: 10.1016/j.socec.2009.08.008

Walsh, S. T., Nico, L. G., Miller, M. W., and Englund, R. A. (2014). "Risk analysis and management alternatives for the prevention and mitigation of nonindigenous fishes and other aquatic macrofauna in freshwater habitats of Micronesia," in Regional Biosecurity Plan for Micronesia and Hawaii. Vol. II, eds University of Guam and the Secretariat of the Pacific Community, 26-196. Available online at https://www.doi.gov/sites/doi.gov/files/uploads/ pac_regional_biosecurity_plan_for_micronesia_and_hawaii_volume_i.pdf (Accessed April 30, 2018).

Walter, M. (2010). Social Research Methods, 2nd edn. South Melbourne, VIC: Oxford University Press.

Warheit, V. (2010). The Insular Empire. America in the Mariana Islands (film documentary). Available online at http://www.horseopera.org/Insular_Empire_ 2010/?page_id=10 (Accessed April 30, 2018).

Williams, R. (1981). Culture. Glasgow: Fontana Press.

Wilson, R. (2000). Exporting christian transcendentalism, importing Hawaiian sugar: The trans-Americanization of Hawai' i. Amer. Lit. 72, 521-552.

Zimmerman, W. (1998). Jingoes, goo-goos, and the rise of America's empire. Wilson Q. 22:42.

Conflict of Interest Statement: The authors declare that the research was conducted in the absence of any commercial or financial relationships that could be construed as a potential conflict of interest.

Copyright (c) 2018 Campbell and Hewitt. This is an open-access article distributed under the terms of the Creative Commons Attribution License (CC BY). The use, distribution or reproduction in other forums is permitted, provided the original author(s) and the copyright owner(s) are credited and that the original publication in this journal is cited, in accordance with accepted academic practice. No use, distribution or reproduction is permitted which does not comply with these terms. 